\title{
Polychlorinated Dibenzo-p-Dioxins and Dibenzofurans in Lake Sediments from Chinese Schistosomiasis Areas
}

\author{
M.-H. Zheng, ${ }^{1}$ Z-C. Bao, ${ }^{1}$ K.-O. Wang, ${ }^{1}$ H. Yang, ${ }^{2}$ X.-B. $X u^{1}$ \\ 'Research Center for Eco-Environmental Sciences, Chinese Academy of Sciences, \\ P.O. Box 2871, Beijing 100085, People's Republic of China \\ ${ }^{2}$ Hunan Province Environmental Protection Monitoring Station of Dongting Lake, \\ Shangkou Road 221, Yuanjiang City, Hunan, 413100, People's Republic of China
}

Received: 24 April 1997/Accepted: 25 June 1997

Lake $\mathrm{D}$ is located in the south of China. The total area of the lake is about $3,000 \mathrm{~km}^{2}$. The dimension of the lakeland varies greatly with changing of seasons. It is an important source of grain and freshwater fish in China. However schistosomiasis japonica prevailed in this region for a long time, sodium pentachlorophenate(Na-PCP) has been sprayed since the 1960 s to control the spreading of snailborne schistosomiasis. Being contaminants of technical Na-PCP, PCDD/Fs may enter the environment and contribute to human exposure after the treatment. The low water solubilities and high adsorption to sediment of PCDD/Fs do not rule out their movement in the environment. Schecter et al. (1994) compared PCDD/Fs levels in blood and milk in agricultural workers and others following Na-PCP exposure in another schistosomiasis area in China, high levels of PCDD/Fs in exposed persons are evident. But the investigation concerning the contamination of Lake $D$ has not been carried out before this study.

\section{MATERIALS AND METHODS}

The samples were taken from eight different locations distributed over the whole lakeland in March 1995 before spraying Na-PCP that year. Sample 1 and Sample 2 were collected in the areas that were covered with water only in the rainy season and exposed directly to the air in the dry season, while other samples are all from sediments under water.

Samples are air dried and sieved $(\phi 2 \mathrm{~mm})$ to eliminate any solid objects. Ten grams of sieved samples are spiked respectively with $3.5 \mathrm{ng}$ each of eight ${ }^{13} \mathrm{C}$-labelled 2,3,7,8,-substituted PCDD/Fs congeners $2,3,7,8$-TCDD, 1,2,3,7,8-P ${ }_{5}$ CDD, 1,2,3,6,7,8- $\mathrm{H}_{6} \mathrm{CDD}$, OCDD, 2,3,7,8-TCDF, 2,3,4,7,8$\mathrm{P}_{5} \mathrm{CDF}, 1,2,3,4,7,8-\mathrm{H}_{6} \mathrm{CDF}, 1,2,3,4,6,7,8-\mathrm{H}_{7} \mathrm{CDF}$, Cambridge Isotope Laboratories) except that $7.0 \mathrm{ng}$ of OCDD as internal standard. The

Correspondence to: Z.-C. Bao 
samples are extracted with toluene for $24 \mathrm{hr}$ in a Soxhlet extractor. The extracts are concentrated to $2 \mathrm{ml}$ using a rotary evaporator. The bulk of the co-extracted organic materials are removed by successively passing the extract through the following series of chromatographic columns: acid silica, acid-base and silver nitrate silica multilayer, and basic alumina. The columns are prepared and the elution procedures are performed according to Lamparski (1989). Just prior to GC-MS analysis, $4 \mu \mathrm{l}$ of two ${ }^{13} \mathrm{C}$-labelled recovery standards (1,2,3,7,8- $\mathrm{P}_{5} \mathrm{CDD}, \quad 1,2,3,4,6,7,8-\mathrm{H}_{7} \mathrm{CDF}$, Cambridge Isotope Laboratories) of $1.0 \mathrm{ng} / \mu \mathrm{l}$ are added for the quantification of surrogated recovery. One sample blank is analyzed for every eight samples. All analyses are carried out by VG-7070E-HF GC/MS using a $60 \mathrm{~m}$ SP2331 (Supelco) fused-silica column. Quantitation of PCDD/Fs is performed in selected-ion monitoring mode. For each congener, two most abundant molecular cluster ions are measured.

\section{RESULTS AND DISCUSSION}

Table 1 shows the concentrations of the 2,3,7,8-substituted PCDD/Fs in Chinese products of Na-PCP(Bao et al. 1995).

Table 1. PCDD/Fs in Chinese PCP-Na(ng/g sample)

\begin{tabular}{llll}
\hline PCDDs & \multicolumn{4}{l}{ PCDFs } \\
\hline $2378-T C D D$ & 4.0 & $2378-T C D F$ & 3.1 \\
$12378-P_{5}$ CDD & 2.1 & $12378-P_{5}$ CDF & 40.9 \\
& & $23478-P_{5}$ CDF & 2.4 \\
$123478-H_{6}$ CDD & 244 & $123478-H_{6}$ CDF & 76.1 \\
$123678-H_{6}$ CDD & 13.8 & $123678-H_{6}$ CDF & 9.4 \\
$123789-H_{6}$ CDD & 2.1 & $123789-H_{6}$ CDF & 0.3 \\
& & $234678-H_{6}$ CDF & 0.9 \\
$1234678-H_{7}$ CDD & 1702 & $1234678-H_{7}$ CDF & 135 \\
& & $1234789-H_{7}$ CDF & 18.3 \\
OCDD & 12514 & OCDF & 1647 \\
Total PCDDs & 15760 & Total PCDFs & 2260 \\
\hline
\end{tabular}

The results of the lake sediment analyses, expressed in $\mathrm{pg} / \mathrm{g}$ of dry weight(d.w.) for the toxic 2,3,7,8-substituted congeners and also in international toxic equivalence factors (I-TEQ) are given in Table 2. The mean recoveries of the samples are in the range from 62 up to $75 \%$.

The fingerprints of the 2,3,7,8-substituted PCDD/F congeners shown in Table 2 are similar to those shown in Table 1. The congeners OCDD, $1,2,3,4,6,7,8-\mathrm{H}_{7} \mathrm{CDD}$ and $1,2,3,4,6,7,8-\mathrm{H}_{7} \mathrm{CDF}$ are dominating. 
Table 2. Levels of $2,3,7,8$-substituted PCDD/F congeners in the sediments (pg/g d.w.)

\begin{tabular}{|c|c|c|c|c|c|c|c|c|}
\hline & Sample 1 & Sample 2 & Sample 3 & Sample 4 & Sample 5 & Sample 6 & Sample 7 & Sample 8 \\
\hline 2378-TCDD & 22.9 & 623.8 & 26.3 & 22.4 & 39.9 & 6.7 & 9.1 & 4.7 \\
\hline $12378-P_{5} C D D$ & 54.8 & 183.2 & 42.8 & 40.4 & 122.3 & 57.5 & 34.1 & 79.5 \\
\hline $123478-\mathrm{H}_{6} \mathrm{CDD}$ & 214.8 & 131.5 & 149.7 & 125.0 & 26.9 & 47.6 & 20.2 & 14.9 \\
\hline $123678-\mathrm{H}_{6} \mathrm{CDD}$ & 24.7 & ND & ND & 79.5 & ND & ND & ND & 7.6 \\
\hline $123789-\mathrm{H}_{6} \mathrm{CDD}$ & ND & 27.3 & 6.1 & ND & ND & ND & ND & 3.2 \\
\hline $1234678-\mathrm{H}_{7} \mathrm{CDD}$ & 574.6 & 524.8 & 361.2 & 2506.2 & 265.2 & 103.6 & 112.2 & 253.0 \\
\hline OCDD & 218257 & 151225 & 149431 & 48349 & 92761 & 92149 & 98221 & 79899 \\
\hline 2378-TCDF & 19.6 & ND & 11.4 & 2.2 & ND & ND & 3.4 & 1.1 \\
\hline $12378-P_{5} C D F$ & 1.5 & ND & ND & 8.2 & 1.3 & ND & ND & 2.2 \\
\hline $23478-P_{5} C D F$ & 5.8 & ND & 1.7 & ND & ND & ND & ND & 1.2 \\
\hline $123478-\mathrm{H}_{6} \mathrm{CDF}$ & 9.9 & ND & 4.1 & 2.2 & 2.9 & ND & ND & 3.7 \\
\hline $123678-\mathrm{H}_{6} \mathrm{CDF}$ & 5.6 & ND & ND & 2.2 & ND & ND & ND & ND \\
\hline $123789-\mathrm{H}_{6} \mathrm{CDF}$ & ND & ND & ND & ND & ND & ND & ND & ND \\
\hline $234678-\mathrm{H}_{6} \mathrm{CDF}$ & 5.9 & ND & ND & ND & ND & ND & ND & ND \\
\hline $1234678-\mathrm{H}_{7} \mathrm{CDF}$ & 488.6 & 105.2 & 196.0 & 65.4 & 115.5 & 20.4 & 13.7 & 53.8 \\
\hline $1234789-\mathrm{H}_{7} \mathrm{CDF}$ & 402.8 & 35.3 & 187.0 & ND & ND & ND & 9.2 & ND \\
\hline OCDF & 13215 & 1371.2 & 14610 & 1414.0 & 852.2 & 1206 & 252.9 & 814.5 \\
\hline$\Sigma$ I-TEQS & 326.9 & 890.5 & 237.2 & 139.5 & 201.5 & 134.8 & 128.3 & 130.2 \\
\hline
\end{tabular}


The ratios of the PCDF/PCDD in the sediments are relatively lower compared to that of PCDF/PCDD in the products of Na-PCP. This phenomenon can be explained by the suggestion that the sunlight photolysis rates of PCDFs in nature water are enhanced by indirect or sensitized photoreactions of chemicals naturally occurring in water (Dung et al., 1994), and PCDFs are photochemically less stable than PCDDs (Wagenaar et al., 1995).

The high values for toxic equivalents of PCDD/Fs of the sediments suggested that the contamination situation would be more serious if PCDD/Fs were distributed on adjacent areas by flooding events and by transport throughout rivers. Chinese scientists are concerned about dioxin contamination and steps have been taken to replace Na-PCP as molluscacide.

Acknowledgments. This study was supported by National Natural Science Foundation of China. Grant no. 29677025.

\section{REFERENCES}

Bao Z-C, Wang K-O, Kang J-X, Zhao L-W (1995) Analysis of polychlorinated dibenzo-p-dioxins and polychlorinated dibenzofurans in pentachlorophenol and sodium pentachlorophenate. Environ Chem(China) 14:317-321

Dung MH, O'Keefe PW (1994) Comparative rates of photolysis of polychlorinated dibenzofurans in organic solvents and in aqueous solutions. Environ Sci Technol 28:549-554

Lamparski LL, Nestrick TJ (1989) Analytical Methodology of the Dow Chemical Company for the determination of selected chlorinated dibenzo-p-dioxins and dibenzofurans in stack gas effluent matrices. Chemosphere 19:1165-1177

Schecter A, Jiang K, Päpke O, Fürst P, Fürst C (1994) Comparison of dibenzodioxin levels in blood and milk in agricultural workers and others following pentachlorophenol exposure in China. Chemosphere 29:2371-2380

Wagenaar WJ, Boelhouwers EJ, de Kok HAM, Groen CP, Govers HAJ, Olie K, de Gerlache J, de Rooij CG (1995) A comparative study of the photolytic degradation of octachlorodibenzofuran (OCDF) and octachlorodibenzo-p-dioxin (OCDD). Chemosphere 31:2983-2992 